\title{
Neutron Diffraction Investigation of Residual Stresses in Transverse/Oblique Rail Slices Subjected to Different Grinding Strategies
}

T. Gnäupel-Herold ${ }^{1,2}$

P. C. Brand ${ }^{1}$

H. J. Prask ${ }^{1}$

${ }^{1}$ U.S. DEPARTMENT OF COMMERCE
Technology Administration
Center for Neutron Research
National Institute of Standards
and Technology
Gaithersburg, MD 20899
${ }^{2}$ University of Maryland
Department of Materials and
Nuclear Engineering

QC 


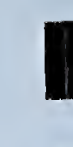




\title{
Neutron Diffraction Investigation of Residual Stresses in Transverse/Oblique Rail Slices Subjected to Different Grinding Strategies
}

\author{
T. Gnäupel-Herold ${ }^{1,2}$ \\ P. C. Brand ${ }^{1}$ \\ H. J. Prask ${ }^{1}$ \\ ${ }^{1}$ U.S. DEPARTMENT OF COMMERCE \\ Technology Administration \\ Center for Neutron Research \\ National Institute of Standards \\ and Technology \\ Gaithersburg, MD 20899 \\ ${ }^{2}$ University of Maryland \\ Department of Materials and \\ Nuclear Engineering
}

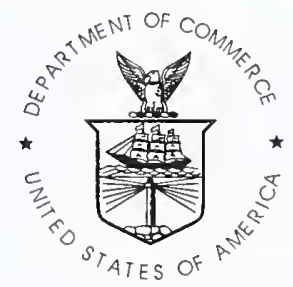

U.S. DEPARTMENT OF COMMERCE William M. Daley, Secretary

TECHNOLOGY ADMINISTRATION Gary R. Bachula, Acting Under Secretary for Technology

NATIONAL INSTITUTE OF STANDARDS 


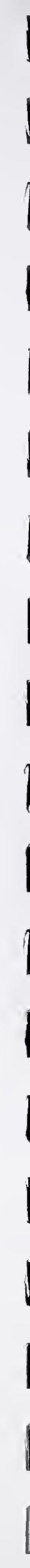




\title{
Neutron Diffraction Investigation of Residual Stresses in Transverse/Oblique Rail Slices Subjected to Different Grinding Strategies
}

\author{
T. Gnäupel-Herold ${ }^{1,2}$, P..C. Brand ${ }^{1}$, H.J. Prask ${ }^{1}$ \\ ${ }^{\prime}$ National Institute of Standards and Technology (NIST), Center for Neutron Research \\ ${ }^{2}$ University of Maryland, Department of Materials and Nuclear Engineering
}

Keywords: Railroad Track; Residual Stress; Neutron Diffraction.

\begin{abstract}
Using the Double Axis system for Residual stress, Texture, and Single crystal analysis (DARTS) at NIST, neutron diffraction residual stress measurements were carried out in the head region of five pairs of transverse and oblique cut slices of railroad track, each having a thickness of $6.35 \mathrm{~mm}$. The slices were taken from a $300 \mathrm{HB}$ rail of CFI $136 \mathrm{RE}$ size. All slices except one unworn reference piece had the same accumulated tonnage but were ground in different intervals. The measurements confirm the results previously found which indicated the existence of high sub-surface residual tensile stresses, while the region close to the wheel-rail contact line shows high residual compressive stresses.
\end{abstract}

\section{Introduction}

Under Project Plan Agreement (PPA) RR-19 with the Office of Research and Development, Federal Railroad Administration (FRA), the John A. Volpe National Transportation Systems Center has been conducting a long-term research project on rail integrity. Over the past 20 years the development of high strength alloys and the use of lubrication has lead to a significant prolongation of rail wear life [1-3]. Although wear remains the principal life limiting factor the focus of attention with respect to rail safety and integrity has shifted to crack failure induced by long-term rolling contact fatigue. This is additionally amplified by the strong interest of the industry to further increase axle loads and speed.

A main source of such service-induced damage is the concentration of very high contact stresses on the rail which leads to subsurface plastic deformation with accumulation of residual stresses of the order of the yield stress. The immediate damage effects are fatigue crack initiation and growth. Secondary damage effects are initiated by the feeding of material due to plastic flow into the high wear rate gage face as well as longitudinal corrugations which form a wavy structure on the running surface of the rail.

The primary mechanisms extend both to the formation and opening of surface cracks as well as of horizontal cracks located about 6 to $7 \mathrm{~mm}$ below the surface. The latter ones are commonly referred 

to as shell defects and they are comparatively benign in nature since they do not cause rail failure directly but tend to grow in an in-plane direction well below the surface. However, in the case of a preferred rolling direction of the wheel the shell defects tend to grow out of the horizontal plane to form vertical detail fractures which, in turn, can lead to rail failure.

Therefore, considerable attention has been paid to profile control and grinding as means of controlled decrease of contact stresses as well as relocation of the contact path on the rail. Likewise, damaged metal from rolling contact fatigue and corrugations are readily removed. Not as obvious, however, is the influence of grinding on the spatial distribution of the accumulated damage. Three-dimensional fatigue modeling indicates that without grinding the depth at which the maximum damage rate occurs remains constant. On the other hand, the optimal grinding wear rate is able to shift with increasing tonnage the location of the zone with maximum damage to greater depths below the initial surface. Within the framework of this investigation, experimentally determined residual strains and stresses are used as a quantitative measure for the accumulated damage [4-13].

The purpose of this investigation is to determine the effect of grinding strategies on the distribution and magnitude of such service-induced residual stresses. Their importance relies on the fact that they are critical parameters in the estimation of the growth rate of fatigue defects. This information is used to assess rail inspection frequencies to assure defect detection prior to catastrophic rail failure.

Recently, a numerical method [13] has been developed to reconstruct the three-dimensional residual stress state in the rail prior to slicing. The approach is based on a hypothesis that there exists a shakedown stress state that is established by the highest load to which the rail is subjected. The shakedown state is not altered by subsequent loads of lower magnitude and similar path, and it is independent of the axial coordinate [4].

In order to apply the plane stress condition as the underlying condition for this method. the method requires sufficiently thin slices. The knowledge of the in-plane strain states in the transverse slice and in the oblique slice whose coordinate frames are rotated with respect to each other allows then the calculation of the undisturbed three dimensional stress state. This way, both the axial component of residual stress which was completely lost from the transverse slice when it was removed from the rail sample, as well as Poisson effect losses from in-plane components [13] are obtained. This method is an enhancement of the so called Battelle-3D [5] technique which relies on longitudinal and transversal cutting of the rail into more than 200 cubes and rods and recording the strain changes during dicing. The new numerical technique, however, requires only one transverse and one oblique cut slice, and can utilize other methods of strain determination such as neutron diffraction, moiré interferometry or other methods $[5-11,14]$. Neutron diffraction measures strain distributions spatially resolved by probing the interatomic distances in crystalline materials. The latter approach, known as the Transverse/Oblique Slice Thermal Moiré (TOSTM) method consists of removal of transverse and oblique slices approximately $10 \mathrm{~mm}$ thick from the rail sample, face grinding and plating with a heat resistant cladding, photo-etching of a cross grating on the clad surface, stress relief at $482{ }^{\circ} \mathrm{C}$, and determination of the associated in-plane displacements by means of grating interferometry ("moiré") [12]. The TOSTM approach was applied at the State University of New York at Stony Brook under contract number DTRS-57-93-C-00108. However, the comparison between the 


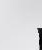


TOSTM results and the neutron diffraction data from a previous investigation [15] did not show the necessary congruence.

The numerical reconstruction of the residual stresses is to be applied to the data obtained from five pairs of rail samples (one each of the transverse and oblique slices) which were taken from a controlled test at the Transportation Technology Center (TTC) in Pueblo, CO.

\section{Specimens}

The specimens consisted of five pairs of $6.35 \mathrm{~mm}$ thick transverse and oblique cut slices of railroad track which were subjected to 39-ton axle loads at the Transportation Technology Center's High Tonnage Loop. The $300 \mathrm{HB}$ rails of CFI $136 \mathrm{RE}$ size were subjected to different combinations of grinding strategies and frequencies:

Table 1: Service history and grinding strategy of the railroad slices.

\begin{tabular}{|l|l|l|}
\hline$\#$ & Description & Transverse/Oblique \\
\hline 1 & Control specimen, no grinding & both \\
\hline 2 & FAST $^{*}$ worn profile, ground every $25 \mathrm{MGT}^{* *}$ & both \\
\hline 3 & Two point contact, ground every $12.5 \mathrm{MGT}^{* *}$ & both \\
\hline 4 & Two point contact, ground every $25 \mathrm{MGT}^{* *}$ & both \\
\hline 5 & New rail specimen, not installed in track & both \\
\hline
\end{tabular}

${ }^{*}$ FAST $=$ Facility for Accelerated Service Testing

${ }^{*}$ MGT $=$ Million Gross Tons

\section{Measurement Technique}

Steel is a crystalline material. Due to the $\gamma-\alpha$ phase transition during cooling down from the hotrolling temperature to room temperature and associated re-nucleation and growth, it is also a relatively fine grained material. This makes steel ideally suited for diffraction experiments.

Neutron diffraction is a technique [14-19] whereby the crystallographic lattice spacing is measured with great precision using Bragg's Law:

$$
2 d \sin \theta=n \lambda
$$

The lattice spacing $d$ is measured by either varying the wavelength $\lambda$ keeping the diffraction angle $\theta$ fixed or by varying $\theta$ and keeping $\lambda$ fixed.

For this experiment neutron radiation from a steady state reactor is used. A white neutron beam containing many neutron wavelengths is diffracted by a [022] oriented copper single crystal $(d=$ 

$1.2780 \AA$ ), at a monochromator diffraction angle of $\theta_{\mathrm{m}} \approx 41.5^{\circ}$. According to equation (1), this yields neutron wavelengths of $\lambda \approx(1.68,0.84$ and 0.56$) \AA$ for $n=1,2$ and 3 respectively. Neutrons with a wavelength of $\lambda=1.68 \AA$ will be diffracted from the $\mathrm{Fe}(211)(d \approx 1.17 \AA)$ lattice planes in the steel at a diffraction angle of $\theta \approx 45^{\circ}$, leading to a total scattering angle of $2 \theta \approx 90^{\circ}$. This choice of monochromator angle and sample reflection (hkl) is suggested by the optimal combination of

a) the particular wavelength that contributes most to the diffracted intensity (in this case 1.68 $\AA$ )

b) the most intense sample reflection

c) the instrumental contribution to the full width at half maximum of the sample reflection (hkl) which should be minimal.

The monochromatic beam is cut down in size by a series of neutron absorbing apertures to a final size of $3 \times 3 \mathrm{~mm}^{2}$ and led over the center of the sample table of the diffractometer. A schematic of this arrangement is shown in fig. 1.

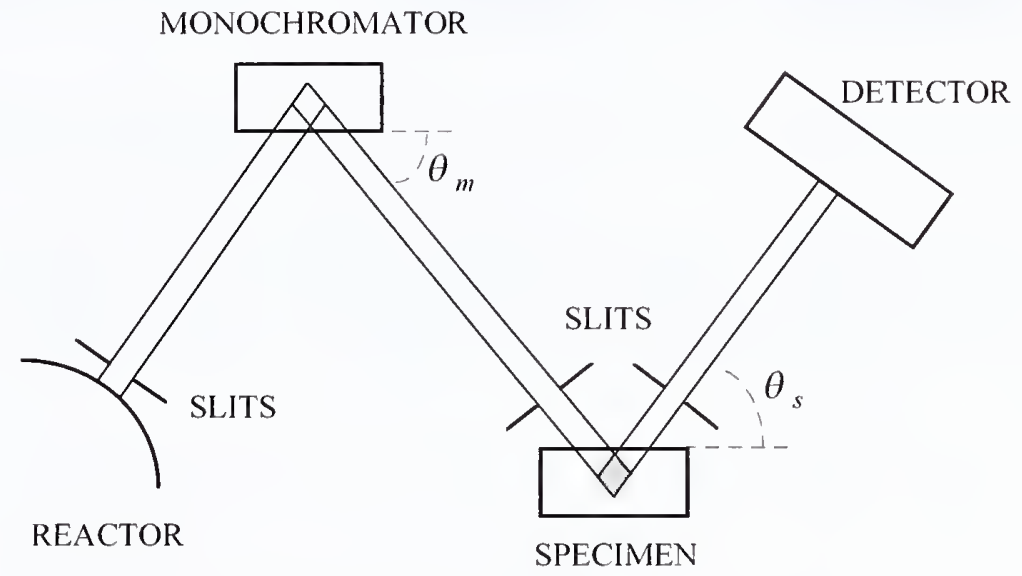

Figure 1: Schematic of the measurement.

On the sample table an $x, y, z$ translation stage (range: $150 \mathrm{~mm} \times 150 \mathrm{~mm} \times 200 \mathrm{~mm}$ ) is mounted. On top of the translation stage the sample is mounted in a device that allows the sample to be put in different orientations (figure 2). 



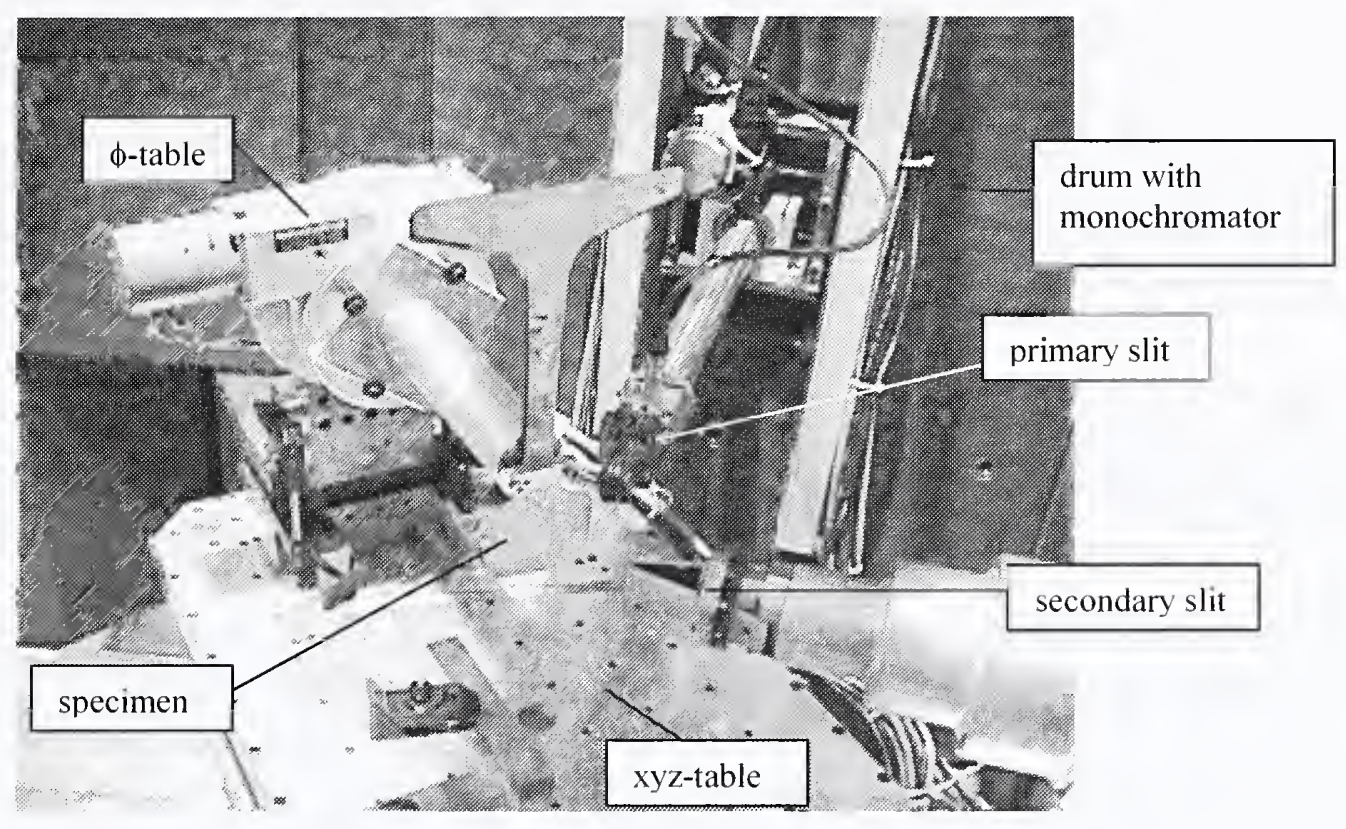

Figure 2: Rail slice on the xyz table. The specimen is mounted on an extra $\phi$-table to bring the sample into arbitrary $\phi$-positions.

The configuration used in the present experiments is one in which a $100 \mathrm{~mm}$ wide linear position sensitive detector "sees" a range of angles simultaneously, and consequently cuts down significantly on the measurement time. Figure 3 shows a typical experimental profile from a rail slice.

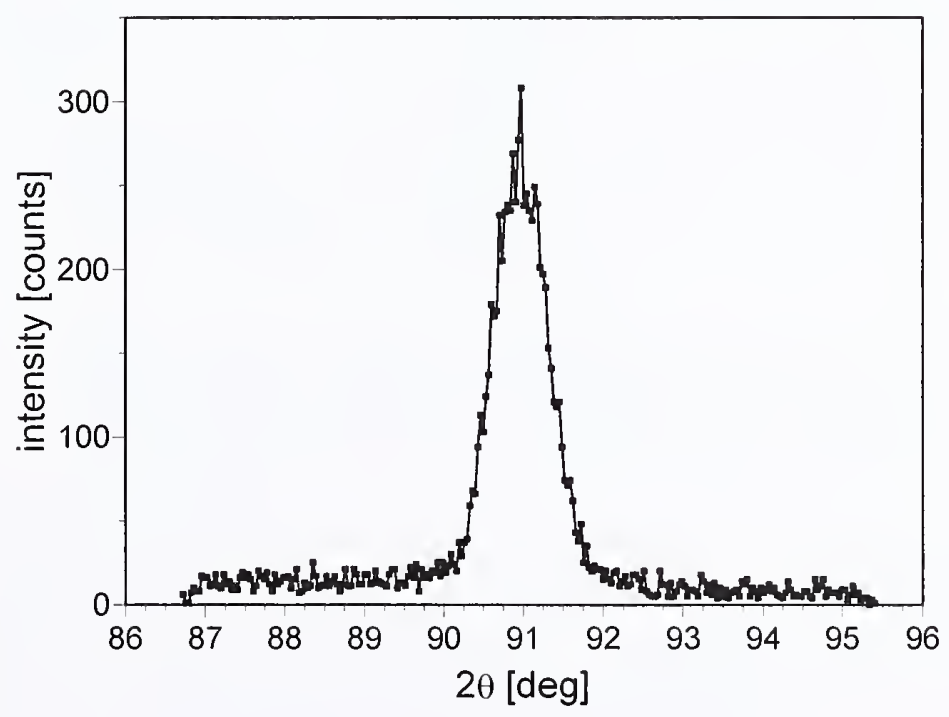

Figure 3: Typical experimental profile of an iron (211) reflection from a railroad slice. 

The detector is positioned at $650 \mathrm{~mm}$ from the specimen. It is observing the diffracted beam at an angle of $2 \theta \approx 90^{\circ}$ and thus receiving neutrons diffracted by the $\mathrm{Fe}(211)$ planes. Close to the rail slice, a vertical aperture (width $3 \mathrm{~mm}$ ) is mounted. This aperture limits the lateral width of the beam that is actually diffracted over the entire penetration of the incident beam. The combination of incident beam aperture and diffracted beam slit selects a cubic sampling volume of $3 \mathrm{~mm} \times 3 \mathrm{~mm}$ $\times 3 \mathrm{~mm}$. Due to divergence (both horizontally and vertically) in the diffraction geometry the true sampling volume is about equal to $3.4 \mathrm{~mm} \times 3.4 \mathrm{~mm} \times 3.4 \mathrm{~mm}$.

The diffraction pattern collected by the position sensitive detector is fitted with a Gaussian/Lorentzian profile. The fitted peak position is then translated into a diffraction angle and subsequently into a $d$-spacing using a set of calibration constants that have been determined in a separate calibration procedure.

For a given orientation of the specimen the lattice spacing is measured in a particular direction within the specimen. This direction is expressed by the scattering vector $\mathbf{Q}$, which has the direction of the bisector of the incident and diffracted beams. The direction of $\mathbf{Q}$ in the specimen axis system is defined by the angles $\phi$ and $\psi$ (see figure 4). The angle $\psi$ is defined as the angle between $\mathbf{Q}$ and the $z$ axis. The angle $\phi$ is defined as the angle between the orthogonal projection of $\mathbf{Q}$ onto the $x, y$ plane and the $x$ axis (see figure 4).

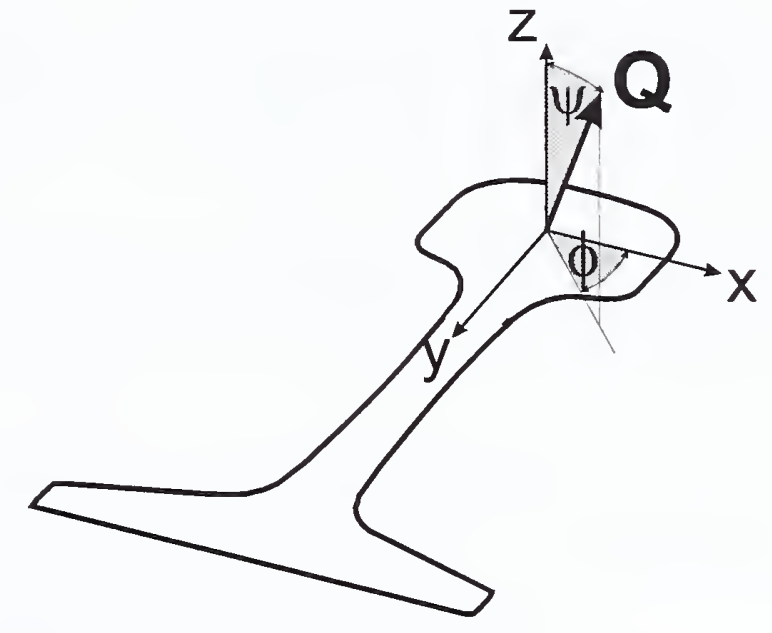

Figure 4: Orientation of the scattering vector $\mathbf{Q}$ in the sample coordinate system. The angle $\psi$ is the angle between the $\mathbf{z}$-axis and $\mathbf{Q}$. The angle $\phi$ is the angle between the orthogonal projection of $\mathbf{Q}$ onto the xy-plane and the $\mathrm{x}$-axis.

By measuring the lattice spacing for various orientations in the specimen (various orientations of $\mathbf{Q}$ and thus values of $\phi$ and $\psi$ in the specimen axis system) one can use the lattice spacing $d$ as an internal strain gauge for the object under consideration. The quantity one is interested in is the strain $\left(\varepsilon=\Delta d / d=\left(d-d_{0}\right) / d_{0}\right)$ as a function of $\mathbf{Q}$. In order to determine strains from the $d$-spacings, one needs to know the value of the stress free lattice parameter $d_{0}$, which can be obtained from a part of the specimen that is stress free, or from a small coupon of the material that has been extracted from the specimen. From the measured strains one can calculate the stress field if one knows the elastic 

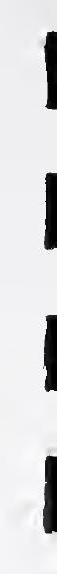
behavior of the material for the diffraction plane employed (expressed by $s_{1}(h k l)$ and $\frac{1}{2} s_{2}(h k l)$ using:

$$
\varepsilon_{\varphi \psi}=\frac{1}{2} s_{2}(h k l)\left[\begin{array}{l}
\left(\sigma_{11} \cos ^{2} \varphi+\sigma_{22} \sin ^{2} \varphi+\sigma_{12} \sin 2 \varphi\right) \sin ^{2} \psi+ \\
\left(\sigma_{13} \cos \varphi+\sigma_{23} \sin \varphi\right) \sin 2 \psi+\sigma_{33} \cos ^{2} \psi
\end{array}\right]+s_{1}(h k l)\left(\sigma_{11}+\sigma_{22}+\sigma_{33}\right)
$$

In many ways this measurement technique is analogous to X-ray diffraction stress analyses. One major difference is the fact that neutron radiation penetrates about a factor of 1000 deeper into steel than X-rays do. This makes it possible to do stress measurements at positions well below the surface of specimens.

From equation (2) it is clear that all six components of the stress tensor can only be obtained by measuring $d$-spacings in six or more independent orientations of $\mathbf{Q}$. The particular set of orientations for the slices 1,2,4 and 5 (table 2) allows us to extract only $\sigma_{\mathrm{xx}}, \sigma_{\mathrm{yy}}$, and $\sigma_{z z}$ from equation 2. No information about $\sigma_{\mathrm{xz}}, \sigma_{\mathrm{xy}}$ and $\sigma_{\mathrm{yz}}$ can be obtained using this set of orientations, but it is important to note that also no assumptions about their value have to be made in order to solve equation 2 . Consequently, the two additional orientations for the slices 3 allowed only the determination of $\sigma_{\mathrm{xy}}$. In order to obtain an areal map of the stresses in the head region, the slices were "covered" by a mesh of densly spaced measurement locations of $3 \times 3 \times 3 \mathrm{~mm}^{3}$ sampling volumes. The number of points in each direction as well as the $\mathbf{Q}$ orientations for each point are shown in table 2.

Table 2: Measurement points and their orientations. A finer mesh was used only for both transverse and oblique slice 3 in the orientations indicated by bold typed letters. The "normal" mesh for slice 3 was measured in all five orientations. All measurements were done with a $3 \times 3 \times 3$ $\mathrm{mm}^{3}$ gauge volume.

\begin{tabular}{|c|c|c|c|c|c|}
\hline \multirow{2}{*}{$\#$} & \multicolumn{2}{|c|}{$\begin{array}{l}\text { Number of measurements } \\
\text { points in } \mathrm{x} \text { direction }\end{array}$} & \multicolumn{2}{|c|}{$\begin{array}{l}\text { Number of measurements } \\
\text { points in y direction }\end{array}$} & \multirow{2}{*}{ Orientations } \\
\hline & $\begin{array}{l}\text { normal mesh } \\
(5 \times 5 \mathrm{~mm})\end{array}$ & $\begin{array}{l}\text { fine mesh } \\
(3 \times 3 \mathrm{~mm})\end{array}$ & $\begin{array}{l}\text { normal mesh } \\
(5 \times 5 \mathrm{~mm})\end{array}$ & $\begin{array}{l}\text { fine mesh } \\
(3 \times 3 \mathrm{~mm})\end{array}$ & \\
\hline 1 & 17 & ---- & 9 & ---- & $(\phi=0, \psi=90) ;(\phi=90, \psi=90) ;(\phi=0, \psi=0)$ \\
\hline 2 & 17 & ----- & 9 & - & $(\phi=0, \psi=90) ;(\phi=90, \psi=90) ;(\phi=0, \psi=0)$ \\
\hline 3 & 17 & 28 & 13 & 13 & $\begin{array}{l}(\phi=0, \psi=90) ;(\phi=90, \psi=90) ;(\phi=0, \psi=0) ; \\
(\phi=30, \psi=90) ; \phi=60, \psi=90)\end{array}$ \\
\hline 4 & 17 & ----- & 9 & ----- & $(\phi=0, \psi=90) ;(\phi=90, \psi=90) ;(\phi=0, \psi=0)$ \\
\hline 5 & 17 & ---- & 9 & ---- & $(\phi=0, \psi=90) ;(\phi=90, \psi=90) ;(\phi=0, \psi=0)$ \\
\hline
\end{tabular}




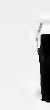


The location of the sampling volumes, their respective size and coordinates as well as the additional measurements on both transverse and oblique slice 3 are clarified in figure 5 .

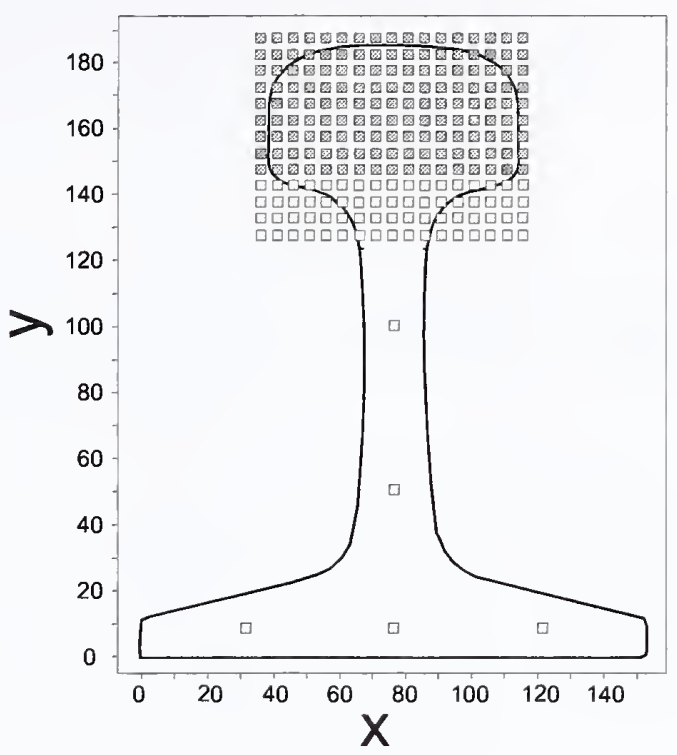

Figure 5: Outline of the unworn transverse slice that was used to establish a mesh of sampling volumes for all transverse slices. The measurement points are $5 \mathrm{~mm}$ apart in both the $\mathrm{x}$ and $\mathrm{y}$ direction. For the oblique slices, the distance in y direction increases to $5 \times \sqrt{2}=7.07 \mathrm{~mm}$. The depth location of all points was $3.17 \mathrm{~mm}$ (half thickness). The dark grey squares represent the points that were measured on all slices, whereas the light grey points were additionally measured on both the transverse and oblique slice 3 (see table 2 for details).

The relationship between the rail outline and the measurement mesh is established by measuring the position of the unworn slice with respect to the xyz-table. Once this position was determined. reference blocks were fixed on the table. Thus. together with a reference bolt on the sample holder device, a three dimensional fixture was established that allowed the accurate $( \pm 0.1 \mathrm{~mm})$ and arbitrary reproducable alignment of every transverse slice. This procedure was then repeated for the oblique slice. It is clear that this procedure relies on the congruence of the outlines of the worn slices with the unworn slice in their base and web regions. Differences in the head region are not relevant in this context. The accuracy of the positions of the sampling volumes in the worn slices is therefore limited by the shape tolerance of the manufacturing process as well as surface roughness due to corrosion.

The stress free lattice parameter $d_{0}$ was obtained from a small coupon $\left(6 \times 6 \times 12 \mathrm{~mm}^{3}\right)$ that was cut off from the extremity of the base region of the unworn slice. It was confirmed by measuring in the same base region of both transverse and oblique slice 3 that this region is relatively stress free and cutting off a small coupon does not affect the stress state in the remaining part of the slice [15]. The $\mathrm{d}$-spacing obtained from the coupon was used as $\mathrm{d}_{0}$ value for all slices. Agreement was also achieved with the values for $\sigma_{7 z}$ which were close to zero using this value for $\mathrm{d}_{0}$. The diffraction elastic constants that were used in this evaluation were: $S_{1}(110)=-1.3 \times 10^{-6} \mathrm{MPa}^{-1}$ and $S_{2}(110) / 2=5.83$ $\times 10^{-6} \mathrm{MPa}^{-1}$. They were calculated from average single crystal elastic constants using a method described in [20]. 


\section{Results}

For each measurement point the $d$-spacings with their respective orientations were entered in equation 2. Equation (2) was then solved in least squares sense for $\sigma_{x x}, \sigma_{y y}, \sigma_{z z}$, and additionally $\sigma_{x y}$ for the slices 3 . The particular choice of mesh points lends itself very well for the presentation of the data in the form of contour plots, which are given in figures 8-19.

\section{Discussion}

At this point we will only discuss the data as we present them in this report. The comparison with modeling efforts will be done at a later date when results are available.

From the present data we can say the following:

1. For all worn slices $\sigma_{x x}$ and $\sigma_{y y}$ show compressive stresses at the top surface of the rail head. These are balanced by tensile stresses in the bulk. This is in agreement with the notion that the top surface has been plastically deformed under the pressure load of the train wheel, not unlike what happens in a process like shot peening. In the beginning of the rail life this is a process that will protect the top surface of the rail against crack initiation. This "protection" is at the expense of the high tensile stresses in the interior. From other investigations [21], there is reason to believe that in the intact rail (i.e. a non sectioned one) the stresses in the longitudinal direction (here $\sigma_{z z}$ ) will also be tensile. If this is the case a hydrostatic tension situation might develop in the interior of the rail head. This would eventually lead to outward cracking of the rail head from the rail interior.

2. Neutron diffraction has proven to be a state-of-the-art, reliable technique that provides accurate data, nondestructively. By comparing the results from specimen \#3 with mesh sizes $3 \times 3 \mathrm{~mm}$ and $5 \times 5 \mathrm{~mm}$ (figures 9 and 11) it becomes clear that all results can be easily reproduced and that a mesh size of $5 \times 5 \mathrm{~mm}$ is sufficient. It can also be concluded that a gauge volume of $3 \times 3 \times 3 \mathrm{~mm}^{3}$ provides sufficiently high spatial resolution. In future measurements, the size of the sampling volume could even be increased without losing information due to averaging effects.

3. The comparison between specimen \#1 (no grinding) and \#3-4 (grinding with different strategies) shows that grinding does shift the zone of maximum residual stresses to greater depths below the initial surface. Based on these data, model predictions appear to be confirmed. The beneficial effect on rail life is the relocation of the zone with the most accumulated damage (tensile stresses) to greater depths. This is accompanied by reestablishing the stress balance due to an increasing overlap of zones with stresses of opposite signs. 


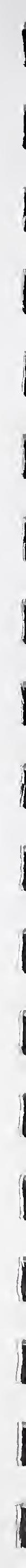




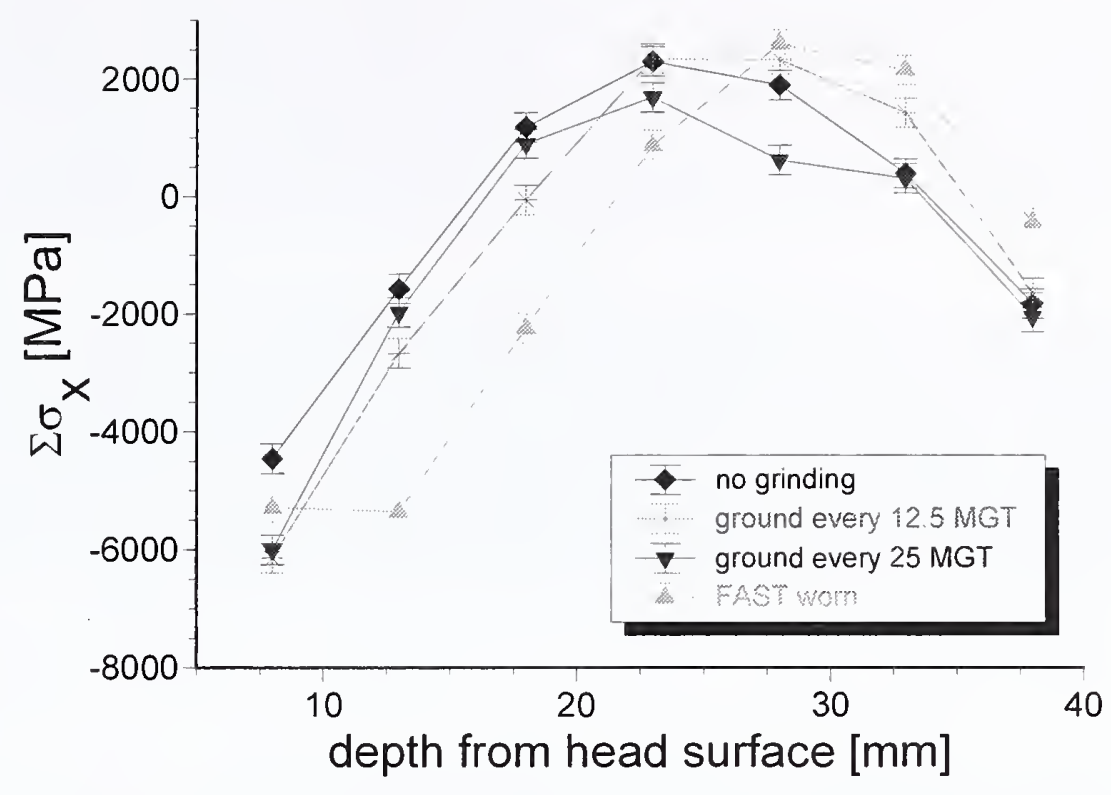

Figure 6 : Summation of $\sigma_{x}$ stress values along the x-direction vs. depth from the running surface.

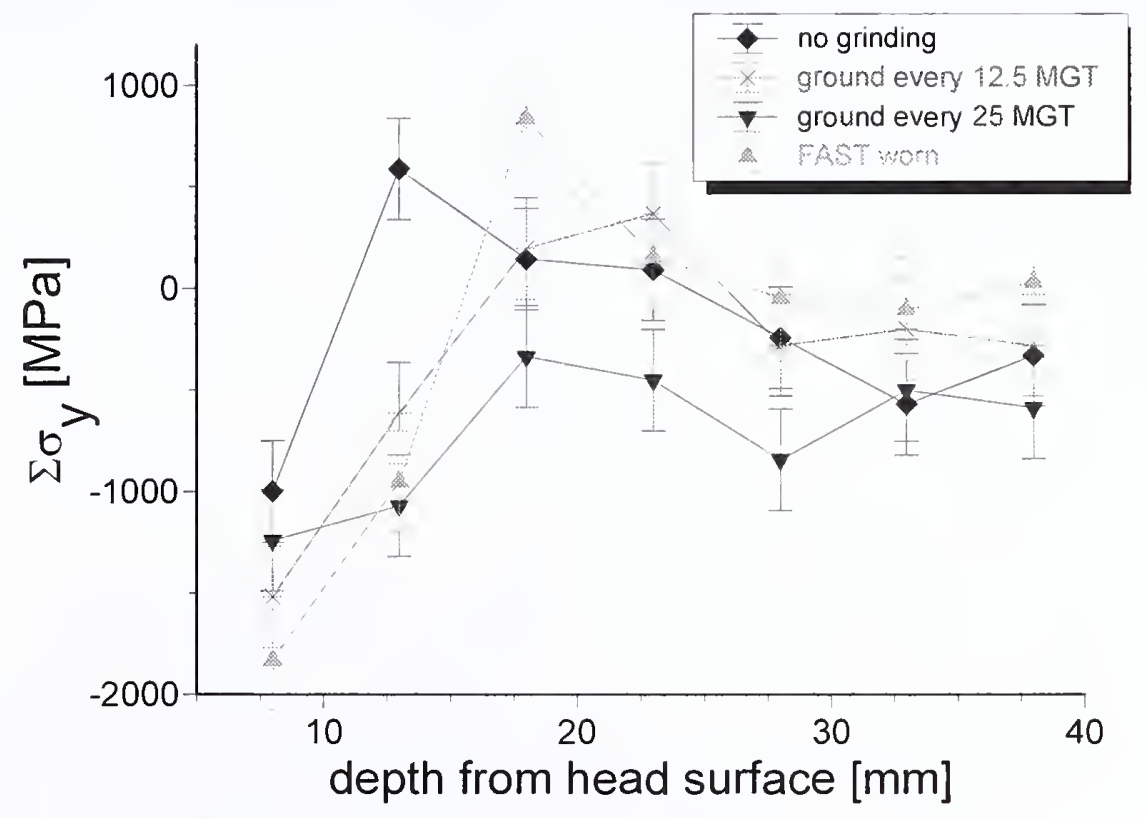

Figure 7 : Summation of $\sigma_{\mathrm{y}}$ stress values along the x-direction vs. depth from the running surface. 


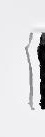

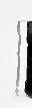

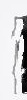

,

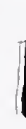


4. The effect of the grinding interval is an increase of the magnitude of the residual stresses if a more frequent grinding is chosen (see figs. 13 and 15). Both the compressive and tensile stresses for the $\mathrm{x}$ - and $\mathrm{y}$-direction in specimen \#3 (ground every 12.5 MGT) are higher than in specimen \#4 (ground every 25 MGT). From figs. 6 and 7 it can be concluded that there is also a slight shift of the entire stress distribution to greater depths with increasing grinding frequency.

5. It can be concluded that grinding has beneficial effects on rail fatigue life. However, the comparison between specimen \#1 (no grinding) and specimens \#3 and \#4 (ground every 12.5 MGT and 25 MGT, respectively) shows that there exists a grinding frequency that is most beneficial for rail life. This optimal grinding frequency represents the compromise between the shortening of rail life by wear (grinding) and by too frequent grinding on one side, and the effect of prolongation of rail life by limiting fatigue damage on the other side.

\section{Recommendations}

Much effort has been and still is put into the slicing technique and the reconstruction of the original, undisturbed stress state in the rail prior to slicing. With the gained knowledge, it appears to be a good idea to attempt a real verification on the head region of an actual piece of railroad rail in which the longitudinal stresses $\left(\sigma_{z z}\right)$ are still preserved. With the new DARTS instrument at NIST such a determination, although difficult, seems feasible. The reliability of reconstruction procedures can be finally established. 


\section{References}

1. O. Orringer, "Control of Rail Integrity by Self-Adaptive Scheduling of Rail Tests," DOT Transportation Systems Center, Cambridge, MA, DOT/FRA/ORD-90/05, June 1990.

2. O. Orringer, Y.H. Tang, J.E. Gordon, D.Y. Jeong, J.M. Morris, and A. B. Perlman, "Crack Propagation Life of Detail Fractures in Rails," DOT Transportation Systems Center, Cambridge, MA, DOT/FRA/ORD-88/13, October 1988.

3. O. Orringer, "Some Suggestions for Adjusting Rail Rest Schedules to Reflect Track Characteristics, Maintenance, Traffic, and Weather," Proc. International Symposium on Rail Steels - Developments, Performance and Manufactming, (B.L. Bramfitt, R.K. Steele, and J.H. Martens, ed.), AIME Iron and Steel Society, 149-159 (1993).

4. J. Orkisz and M. Holowinski, "Prediction of Residual Stress in Rails: Practical Benefits from Theoretical Approach," Rail Quality and Maintenance for Modern Railway Operation, (J. J. Kalker, D.F. Cannon, and O. Orringer, ed.), Kluwer Academic Publishers, Dordrecht, The Netherlands, 1993, pp. 273-296.

5. J.J. Groom, "Determination of Residual Stresses in Rails," Battelle Columbus Laboratories, Columbus, OH, DOT/FRA/ORD-83/05, May 1993.

6. C.H. Cundiff and R.C. Rice, "Comparative Evaluation of Several Alternative Methods for Measuring Rail Residual Stress," Residral Stress in Rails: Effects on Rail Integrity and Railroad Economics - Vol. I: Field Experience and Test Results, (O. Orringer, J. Orkisz. and Z. Swiderski, ed.), Kluwer Academic Publishers, Dordrecht. The Netherlands, 1992, pp. 121-142.

7. G.A. Webster et al., "Neutron Diffraction Determinations of Residual Stress Patterns in Railway Rails," Residnal Stress in Rails, ibid., pp. 143-152.

8. R. Czarnek, J. Lee, and S.-Y. Lin, "Moire Interferometry and its Potential for Application to Residual Stress Measurements in Rails," Residnal Stress in Rails, ibid., pp. 153-167.

9. J. Deputat, J. Szelazek, A. Kwaszcynska-Klimek, and A. Miernik, "Experiences in Ultrasonic Measurement of Rail Residual Stresses," Residıal Stress in Rails, ibid., pp. 169183.

10. M. Bijak-Zochowski, "Investigation of Residual Stress by Penetration Method," Residiral Stress in Rails, ibid., pp. 185-203.

11. R. Radomski, "Residual Stress Measurements at Rail Surface and Inside Rail Head," Residual Stress in Rails, ibid., pp. 205-214.

12. Y.Y. Wang, X. Shen, and F.P. Chiang, "New Experimental Approach for Studying Residual Stresses in Rails," Proc. Ath International Conference on Contact Mechanics and Wear of Rail/Wheel Systems. Vancouver, BC, 1994 (in press). 
13. J. Magiera, J. Orkisz, and W. Karmowski, "Reconstruction of Residual Stresses in Railroad Rails from Measurements Made on Vertical and Oblique Slices," Proc. Ath International Conference on Contact Mechanics and Wear of Rail/Wheel Systems, Vancouver, BC, 1994 (in press).

14. Choi. C.S., Prask, H.J. and Trevino, S.F. "Nondestructive Investigation of Texture by Neutron Diffraction"; J. Appl. Crys., 12, 327-331, 1979.

15. P.C. Brand, H.J. Prask, G.E. Hicho, "Residual Stress in Steel Railroad Track Measured by means of Neutron Diffraction", Report NISTIR 5912, U.S. Department of Commerce, Technology Administration 1996

16. Allen, A.J., Andreani, C., Hutchings, M.T., and Windsor, C.G., NDT International, 14: 249-254, 1981.

17. Hutchings, M.T. and Krawitz, A.D. (editors), "Measurement of Residual and Applied Stress Using Neutron Diffraction"; NATO ASI Series (Vol 216E), Kluwer Academic Publishers (Dordrecht/Boston/London), 1992.

18. Allen, A.J., Hutchings, M.T., Windsor, C.G. and Andreani, C., "Neutron Diffraction Methods for the Study of Residual Stress Fields"; Adv. Physics, 34, 445-473, 1985.

19. P.C. Brand and H.J. Prask, "New Methods for the Alignment of Instrumentation for Residual Stress Measurements by means of Neutron Diffraction," Journal of Applied Crystallography, 27, 164-176, 1994.

20. Bollenrath, F.,Hauk, V. Müller, E. H.(1967), "Zur Berechnung der vielkristallinen Elastizitätskonstanten aus den Werten der Einkristalle", Z. Metallk. 58, 1, 76-82

21. P.J. Webster, G. Mills, X. Wang, W. P. Kang, "Residual Stress Measurements in Rails by Neutron Diffraction", in: J.J. Kalker, D.F. Cannon, O. Orringer (eds.), "Rail Quality and Maintenance for Modern Railway Operation", 307-314, Kluwer Academic Publishers, Dordrecht, The Netherlands, 1993 

Number 1
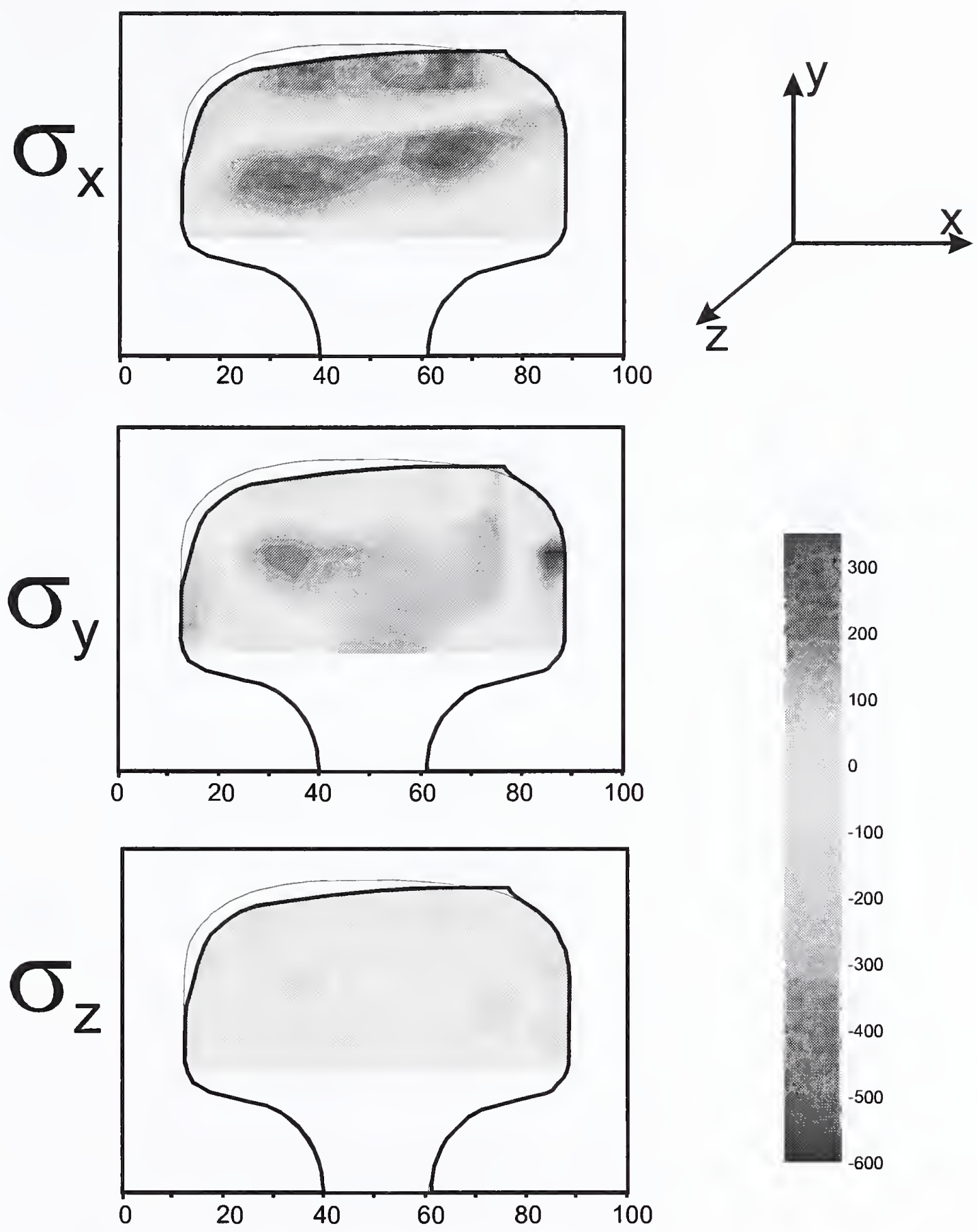

$-100$

$-200$

$-300$

$-400$

$-500$

$-600$

Figure 8: Residual stresses in the transverse slice 1 in units of MPa. Length units are given in mm. 

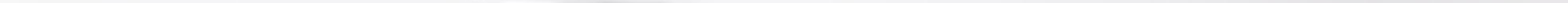

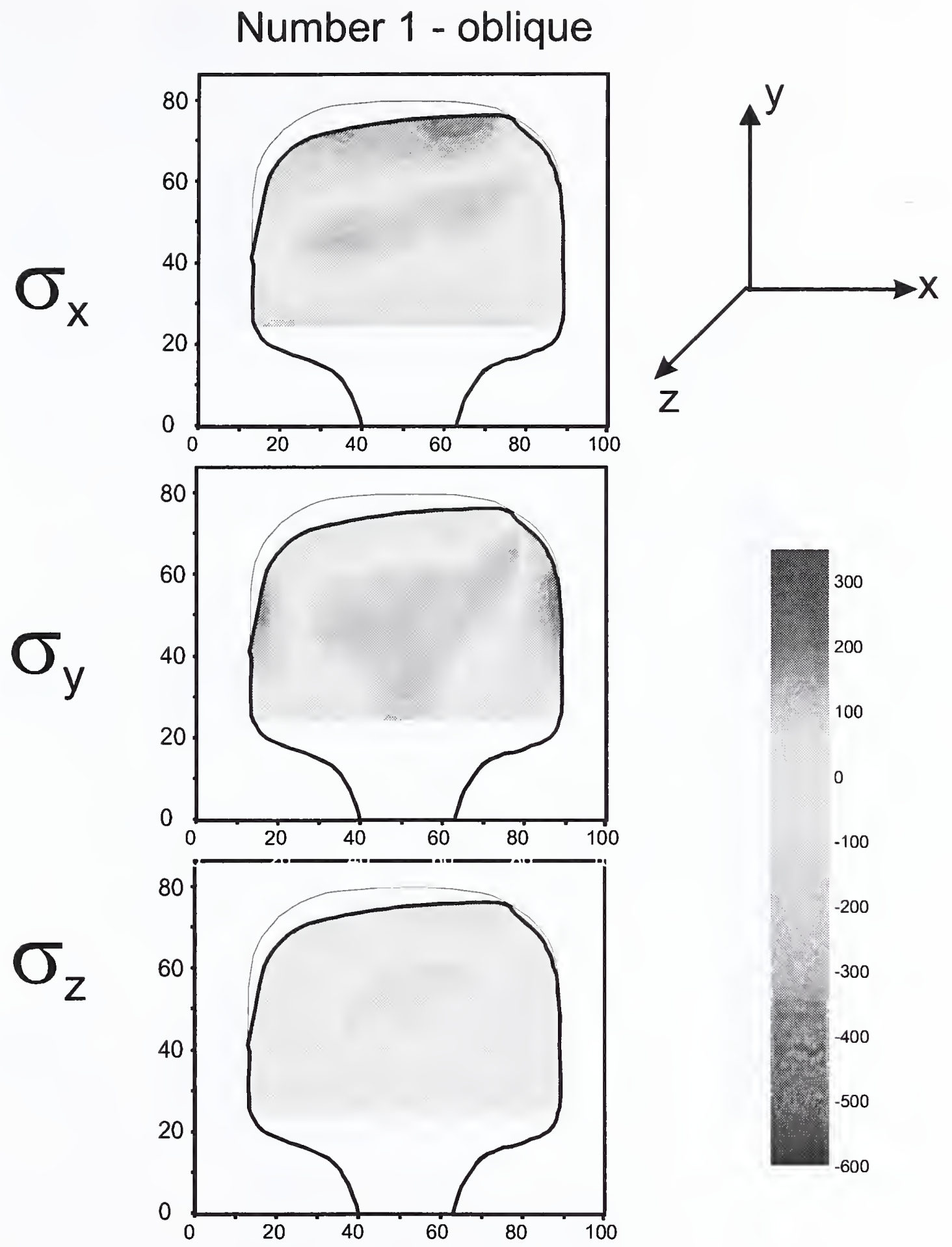

Figure 9: Residual stresses in the oblique slice 1 in units of MPa. Length units are given in mm. 

Number 2
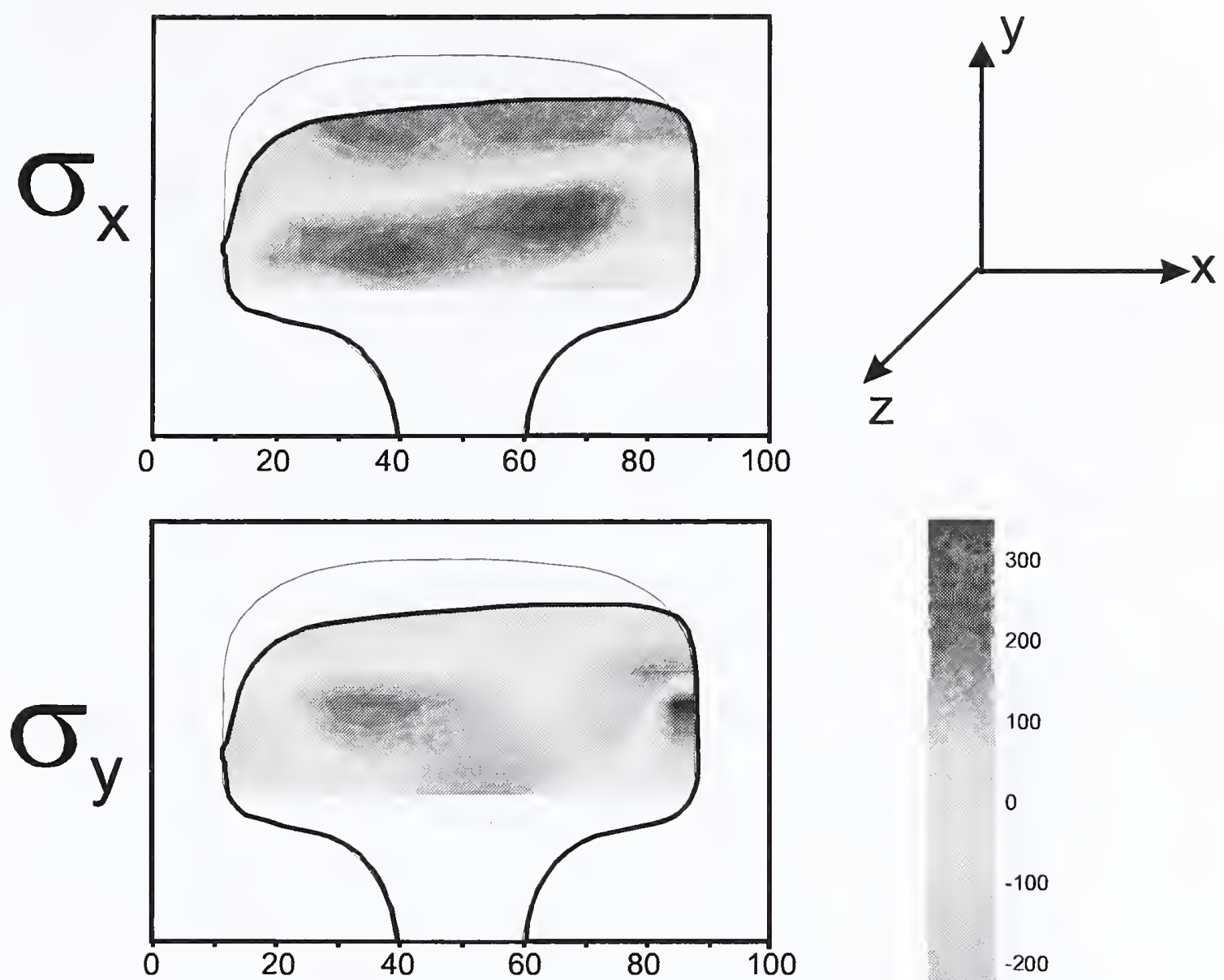

0

$-100$

$-200$

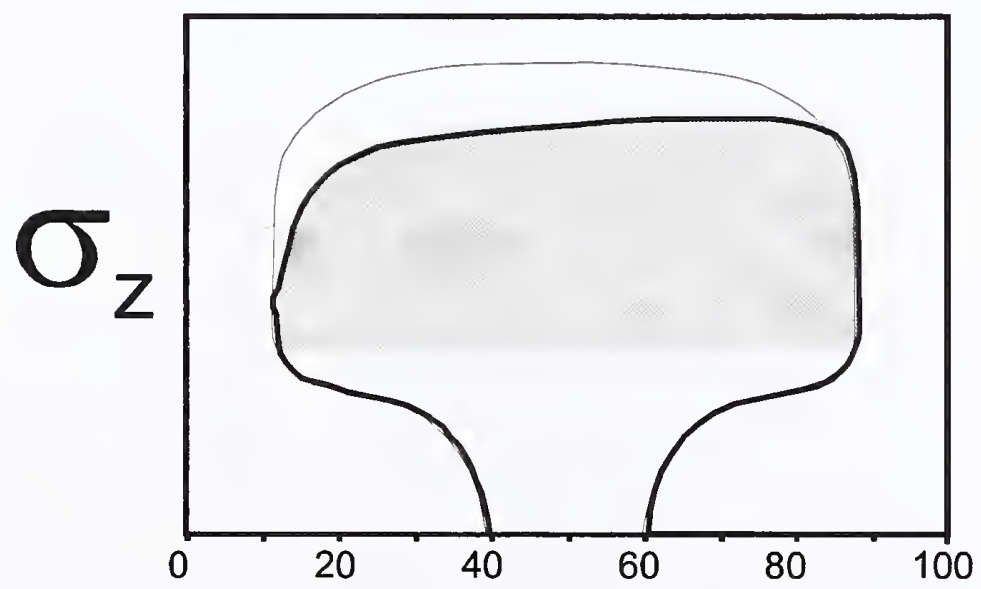

$-300$

$-400$

$-500$

$-600$

Figure 10: Residual stresses in the transverse slice 2 in units of MPa. Length units are given in mm. 



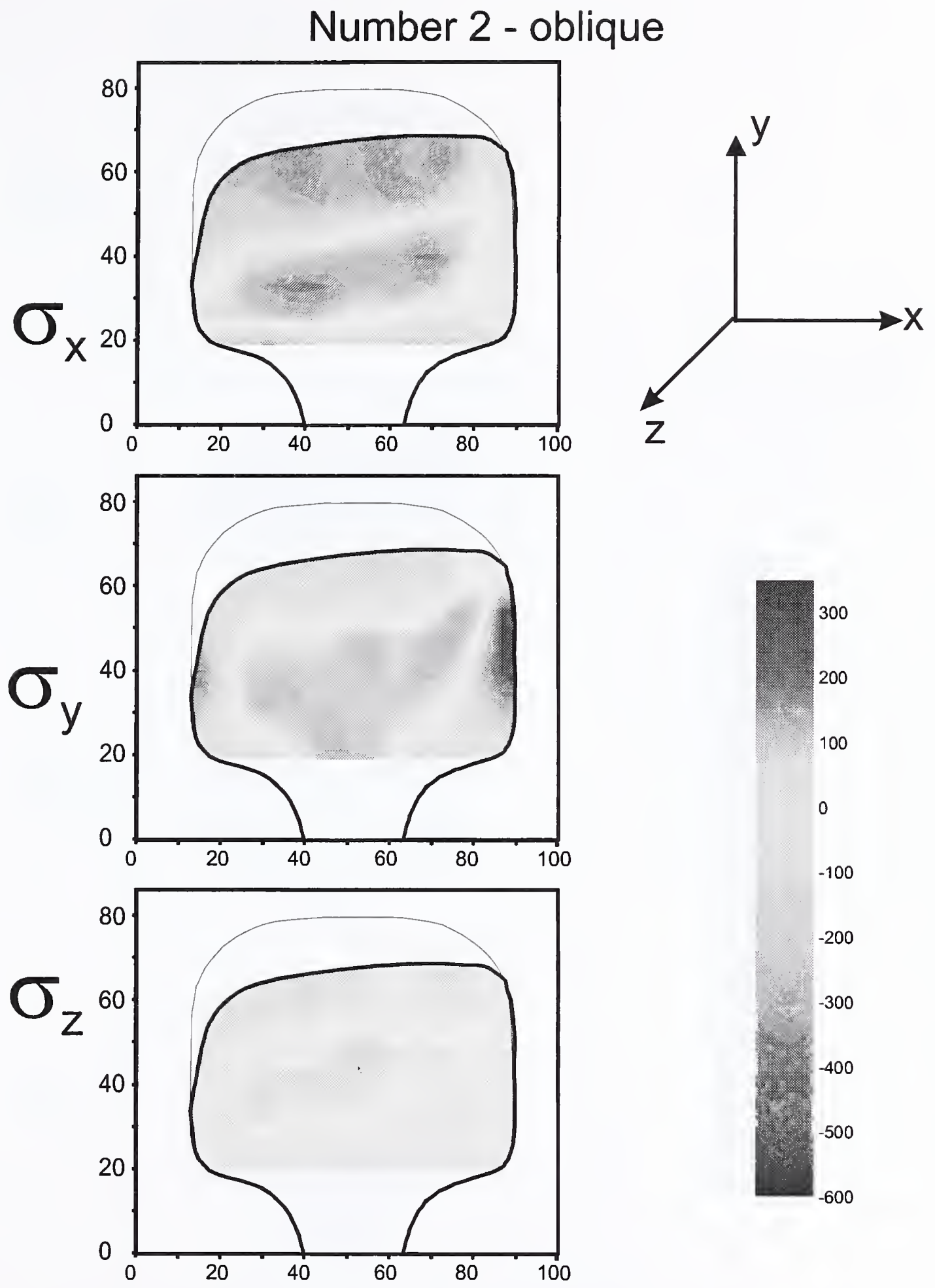

Figure 11: Residual stresses in the oblique slice 2. Length units are given in $\mathrm{mm}$. 


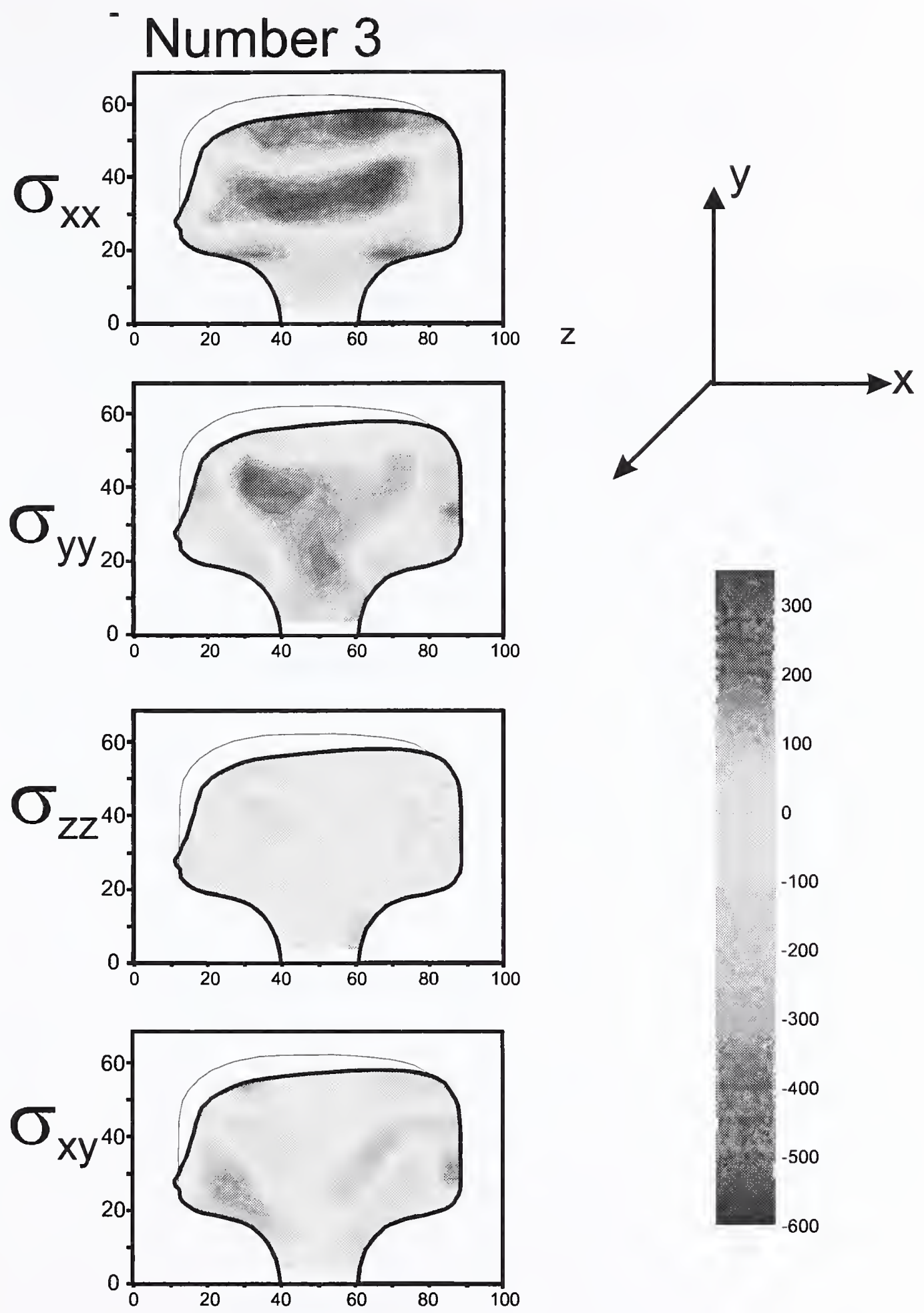

100

0

$-100$

$-200$

$-300$

$-400$

$-500$

$-600$

Figure 12: Residual stresses in the transverse slice 3. Length units are given in mm. 


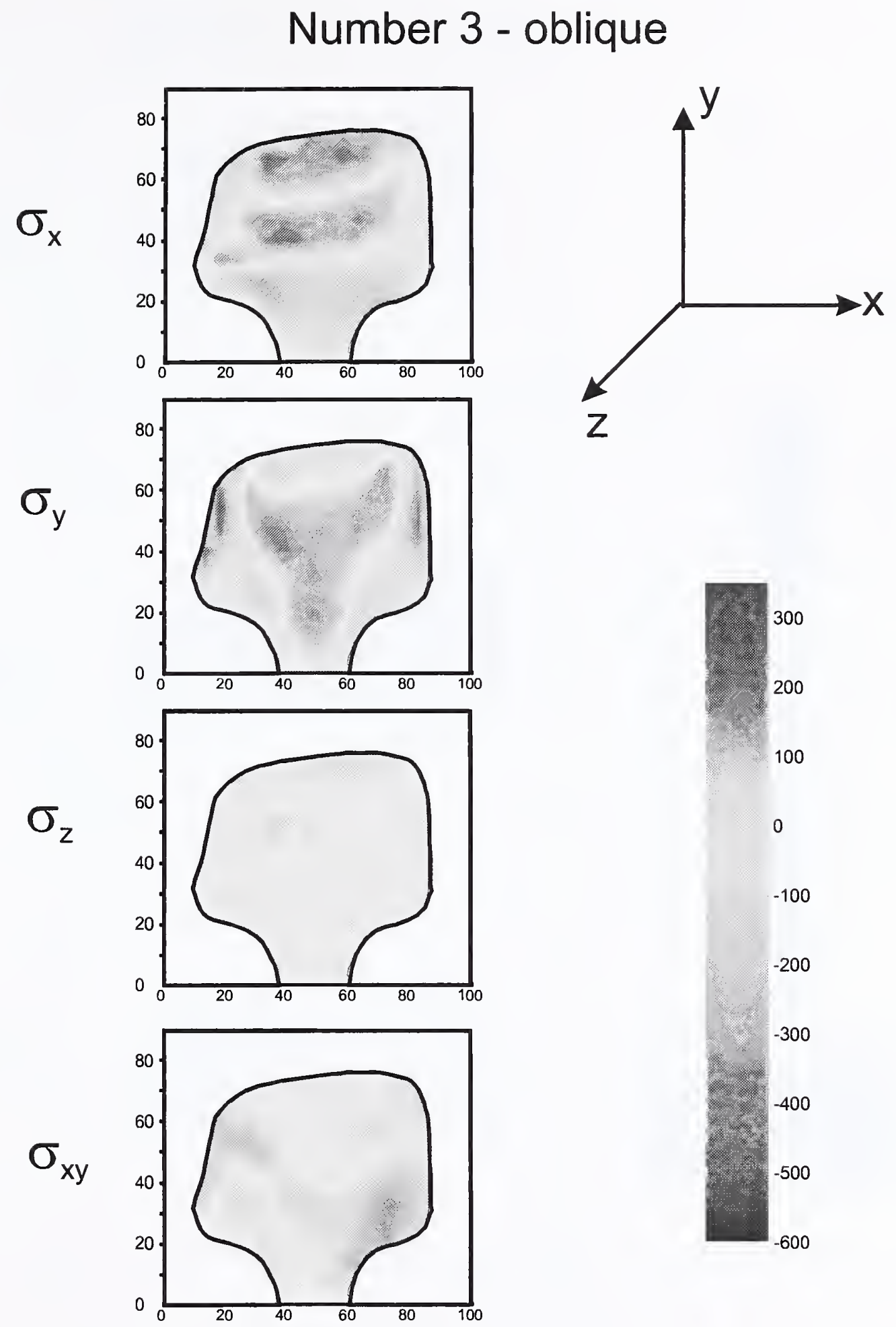

100

0

$-100$

$-200$

$-300$

$-400$

$-500$

$-600$

Figure 13: Residual stresses in the oblique slice 3 in units of MPa. Length units are given in mm. 


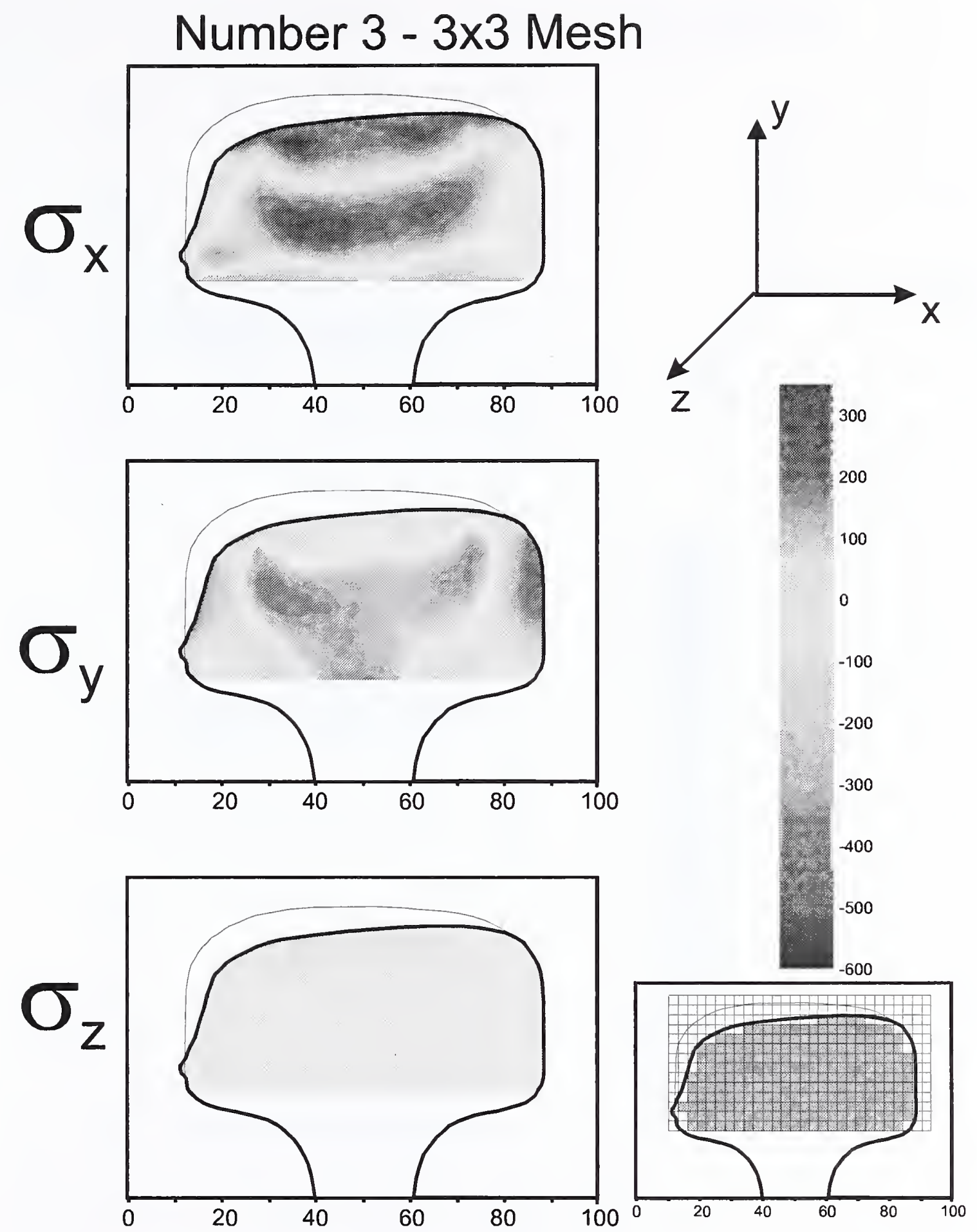

Figure 14: Residual stresses in the transverse slice 3 with the mesh of $3 \times 3 \mathrm{~mm}$ in units of MPa. Length units are given in $\mathrm{mm}$. 


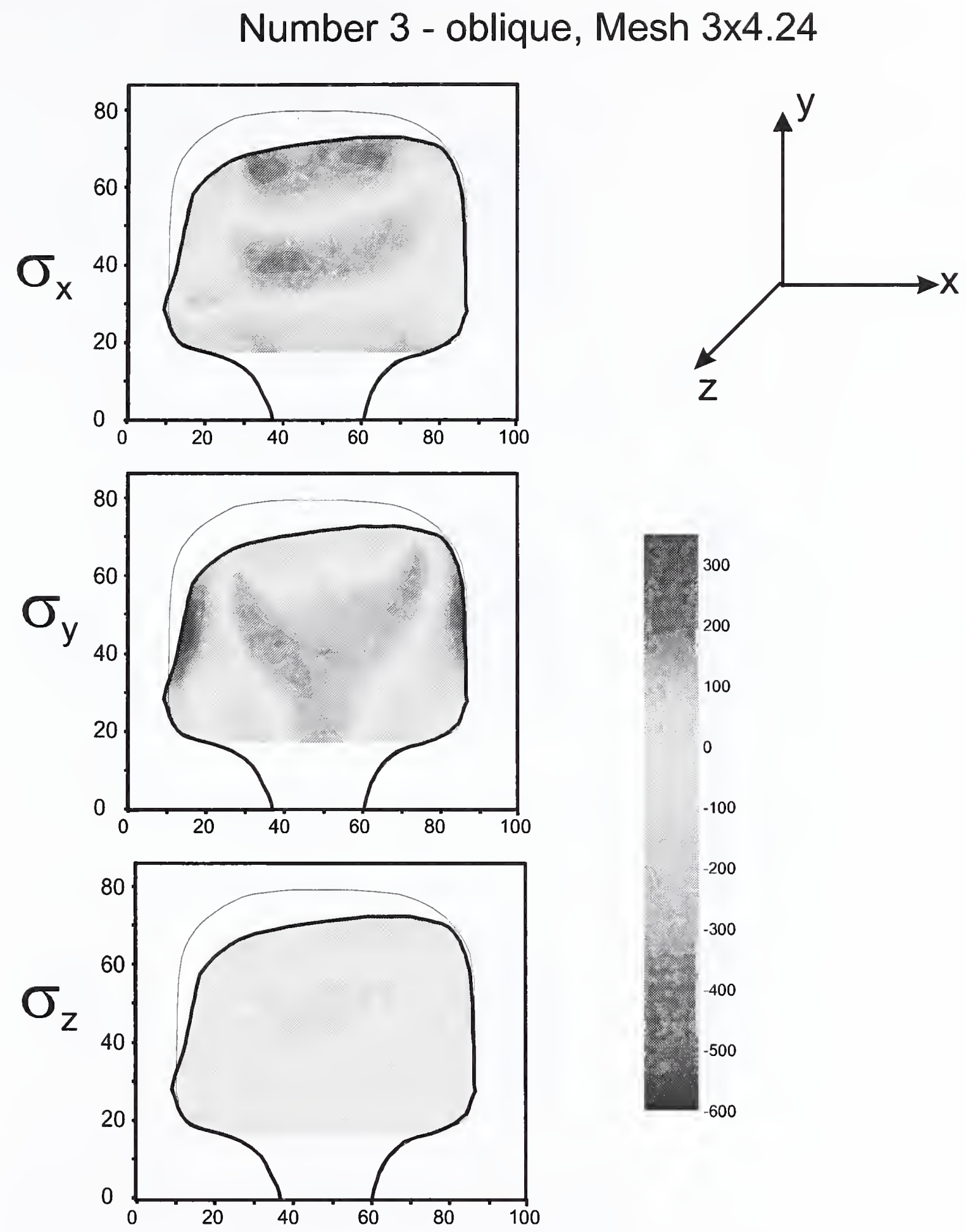

$-200$

$-300$
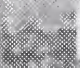

Figure 15: Residual stresses in the oblique slice 3 with the mesh of $3 \times 4.24 \mathrm{~mm}$ in units of MPa. Length units are given in $\mathrm{mm}$. 

Number 4

$\sigma_{x}$
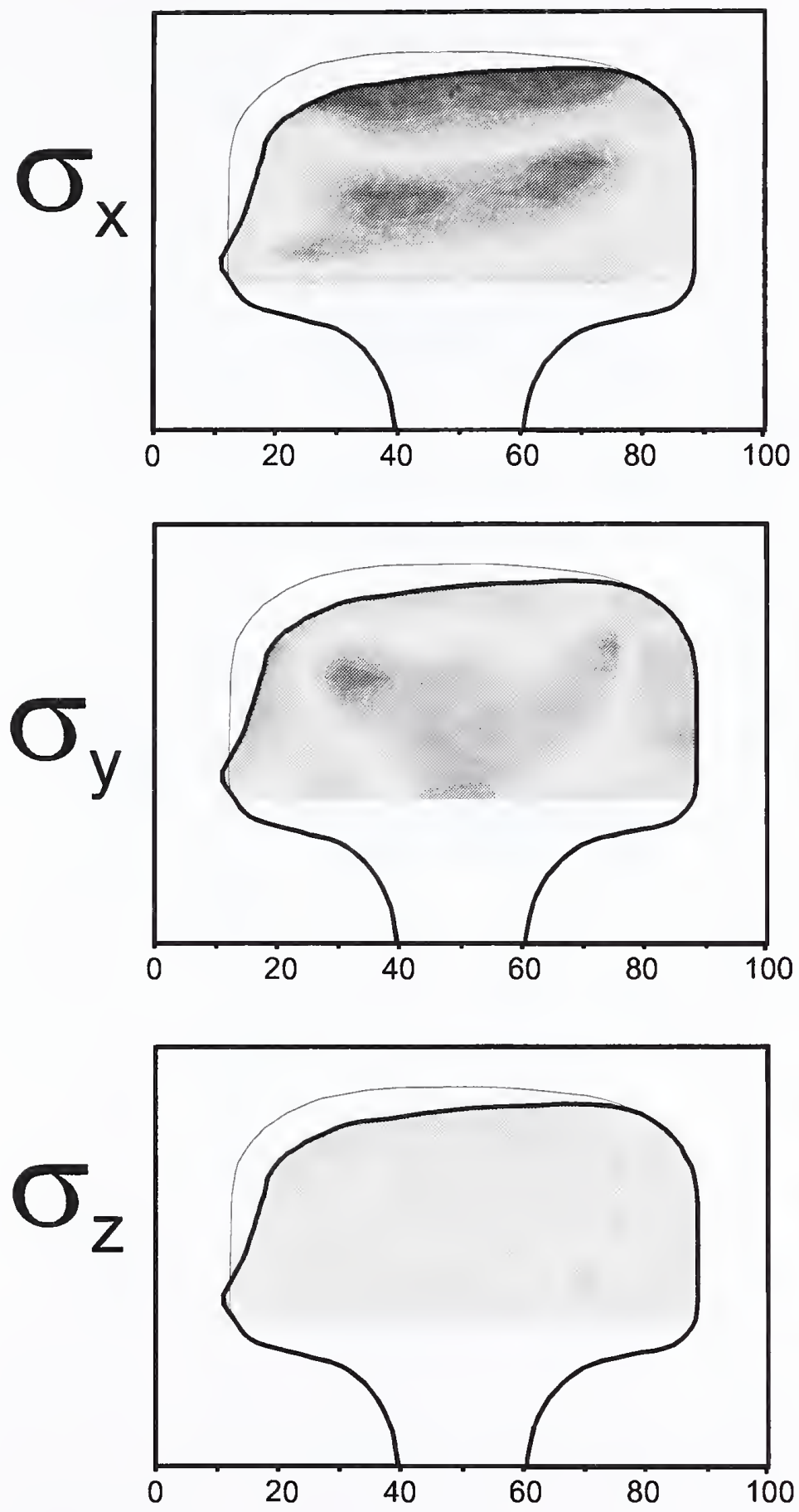

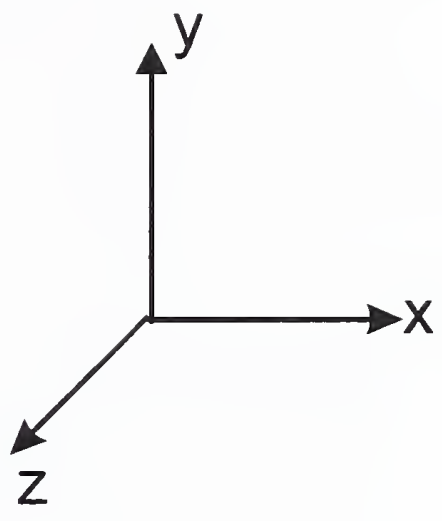

300

200

100

0

$-100$

$-200$

$-300$

$-400$

$-500$

$-600$

Figure 16: Residual stresses in the transverse slice 4 in units of MPa. Length units are given in mm. 



\section{Number 4 - oblique}
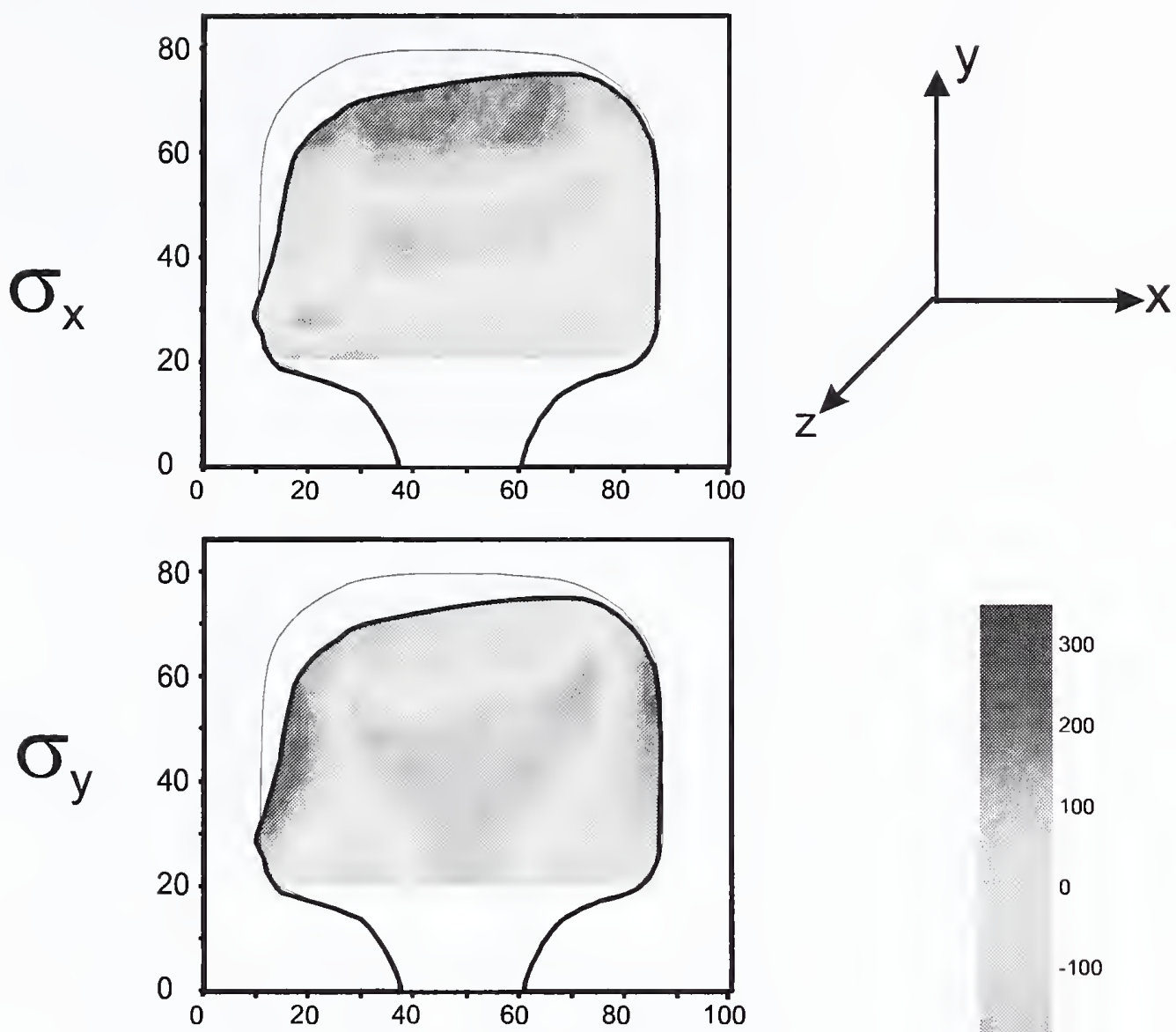

0

$-100$

$-200$
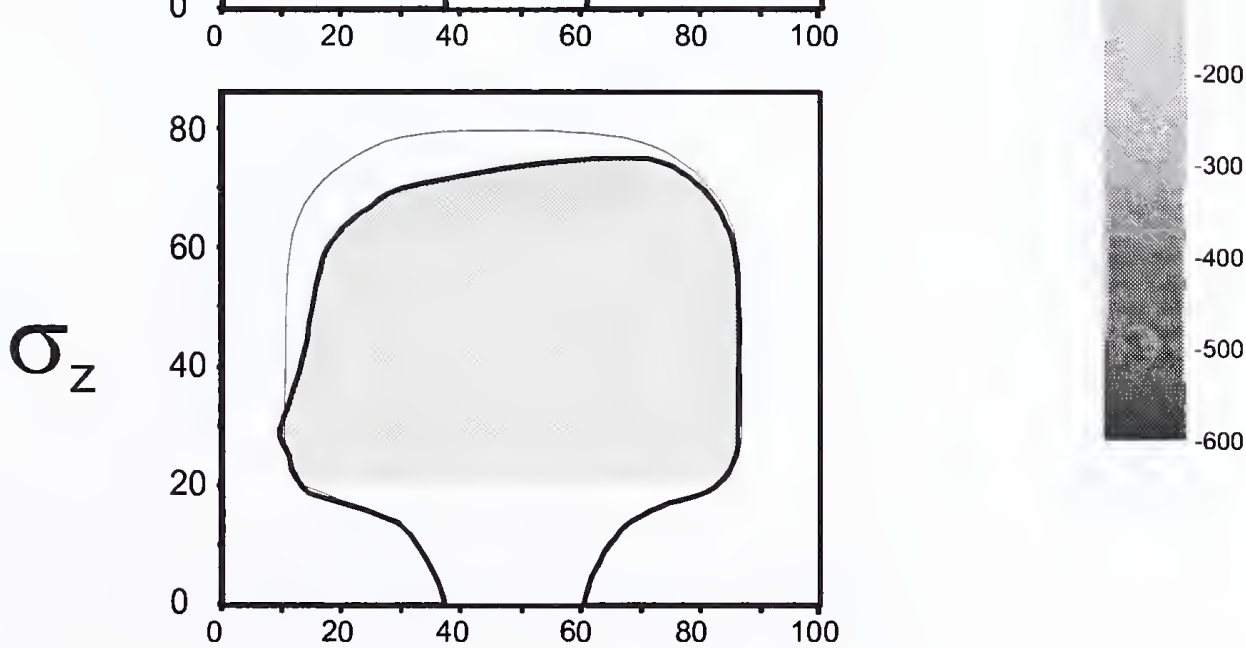

Figure 17: Residual stresses in the oblique slice 4 in units of MPa. Length units are given in mm. 



\section{Number 5 (undeformed)}
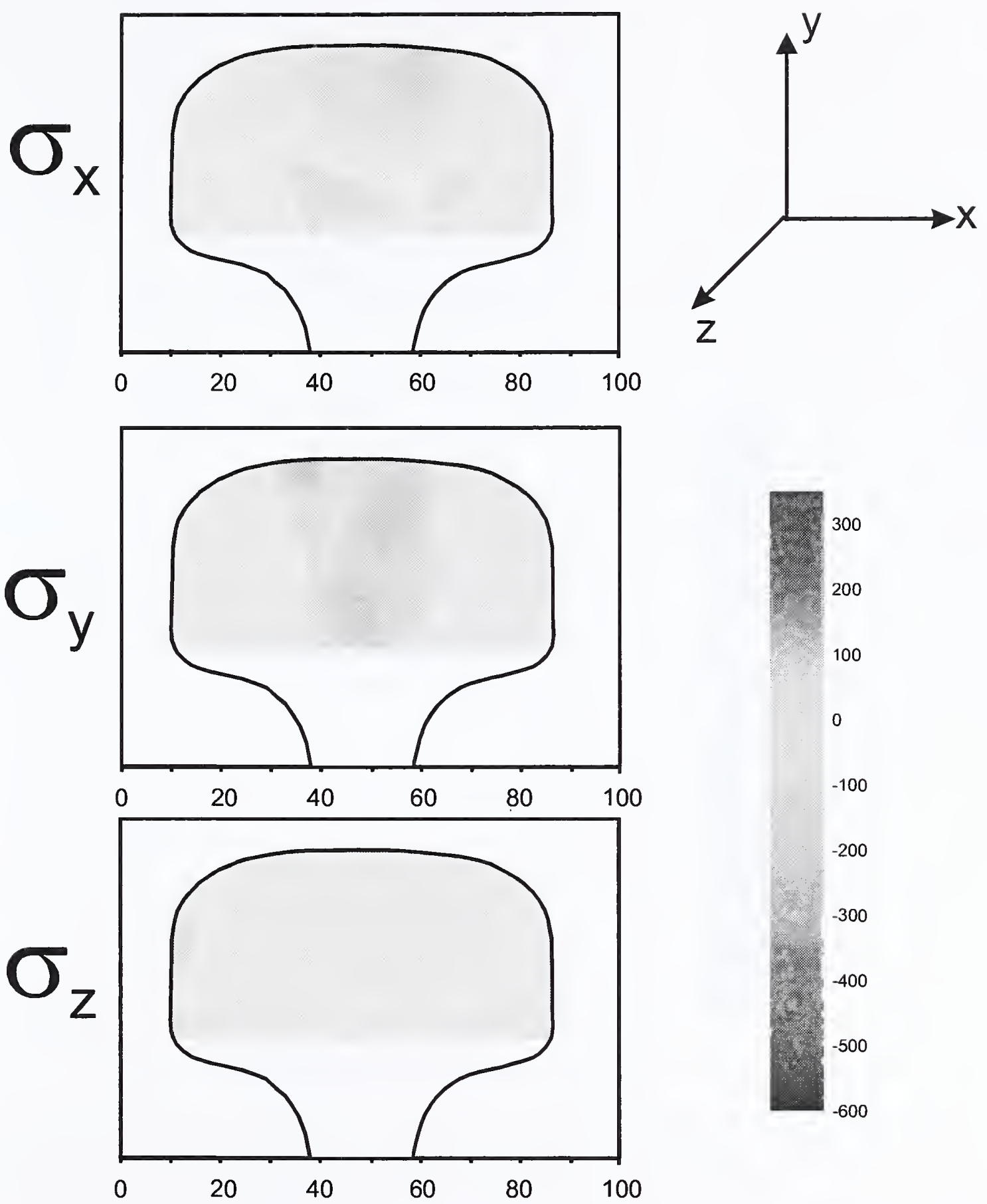

0

Figure 18: Residual stresses in the transverse slice 5 in units of MPa. Length units are given in mm. 


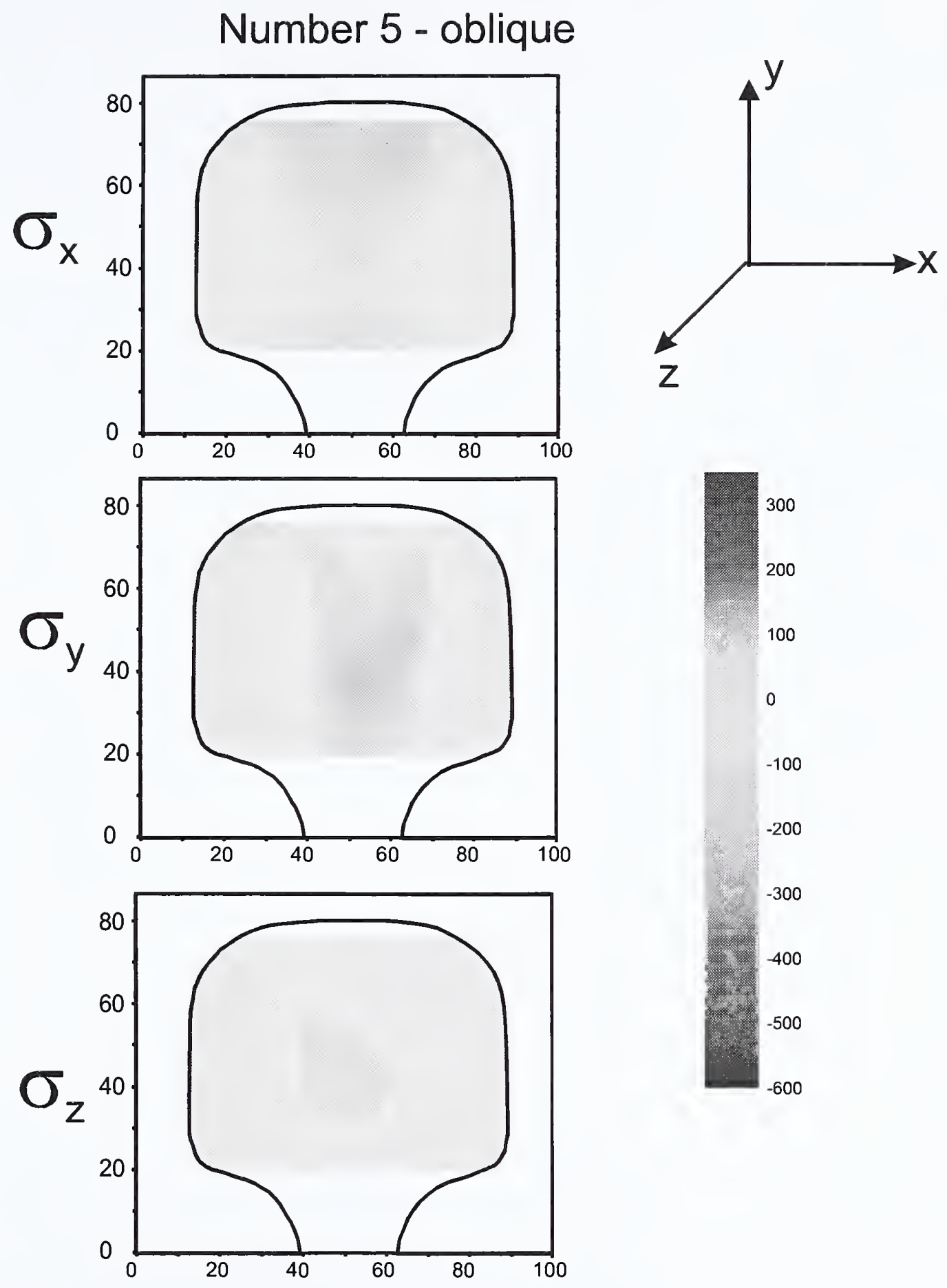

Figure 19: Residual stresses in the oblique slice 5 in units of MPa. Length units are given in mm. 


